\title{
Current Status and Factors Affecting Knowledge Sharing Practices among Health Professionals in Hiwot Fana Specialized University Hospital in Ethiopia
}

\author{
Endris MamoMulate ${ }^{1}$, Lawrence Abraham Gojeh, ${ }^{2, *}$ \\ ${ }^{1}$ Department of Information Technology, Institute of Technology, Jigjiga University, Ethiopia \\ ${ }^{2}$ Department of Information Science, College of Computing and Informatics, Haramaya University, Ethiopia
}

Received March 5, 2020; Revised April 10, 2020; Accepted April 27, 2020

Copyright $₫ 2020$ by authors, all rights reserved. Authors agree that this article remains permanently open access under the terms of the Creative Commons Attribution License 4.0 International License

\begin{abstract}
Knowledge sharing is about sharing relevant task (skills, experiences) among team members or with other people and making the shared knowledge reusable. Hence, the objective of this study was to assess the current status and factors affecting knowledge sharing practices among health professionals in Hiwot Fana Specialize University Hospital in Ethiopia. A Cross-sectional research method with questionnaire was employed for the study. The sample size was 152 categories of health professionals that were: 46 nurses, 18 doctors, 15 radiologists, 26 laboratory technologists, 22 health officers and 26 pharmacists; selected from a population of 268 professionals in the hospital. The sampling technique was stratified simple random sampling. The results showed that the current status of Knowledge Sharing practices by all categories of health professionals was 'high' in areas such as: formal training programs and workshops to share knowledge (3.43); individuals' pleasure to share their know-how, information, working experience and knowledge to colleagues voluntarily (3.81); individuals' pleasure to share freely information and knowledge that improves the hospital performance (4.00) and colleagues awareness of the importance of knowledge sharing in the hospital (3.90). Knowledge sharing was 'very low' based on the non-availability of motivational scheme in the hospital to motivate knowledge sharing (1.74) but 'low' on staffs feeling of motivation to share knowledge in the hospital (2.44). However, there were factors that affected knowledge sharing practices, which included: lack of willingness by colleagues to share their information with other colleagues at all times; lack of awareness on the importance of knowledge sharing in the day- to- day work and lack of intrinsic motivation that staff would gain new ideas, technologies skills or techniques by sharing knowledge. The study concludes that there were variations in the opinions of the categories of health professionals on
\end{abstract}

the current status and factors affecting knowledge sharing practices in the hospital.

Keywords Individual Factors, Organizational Factors, Technological Factors, Health Professionals, Healthcare, Hiwot Fana Specialized University Hospital, Knowledge, Knowledge Sharing Practices

\section{Introduction}

In today's global economy, knowledge is essential in everyday work. Knowledge is skills and practices, which is found in people, organizations and embedded in different artifacts, procedures; as well as stored in different media. Such media as print and non-print alike, as well as resources that employee should possess to effectively execute their tasks [1] \& [2]. People rely on knowledge to perform daily activities and largely communicate ideas both at local and international levels for successful execution of routine responsibilities, activities and knowledge transfer. Knowledge transfer on the other hand is placed on a continuum that is passed from one generation to another. It improves communal activities and engagements, corporate cognitive experiences and competitive advantage, which includes scientific communications.

Whereas, [3] stated that every accomplishment needs some sort of knowledge, because there is nothing which can be performed without knowledge. While knowledge as a source of resource and economy, it should therefore be managed through knowledge management. Knowledge management $(\mathrm{KM})$ is a popular concept that plays an important role in an organization by improving performance and gaining competitive advantage. It helps in 
improving the systematic management of knowledge within healthcare organizations, industries, educational institutions, governmental and business organizations [4]; [5] \& [6].

Healthcare organizations are increasingly becoming a knowledge-based community that depends critically on knowledge management to improve the healthcare delivery services through knowledge sharing (KS), to as well make or produce best practices and benefits to the organizations [7] \& [8]. KS again, is a deliberate act that makes knowledge reusable between two or more parties such as individuals, organizations or parts of an organization; through the knowledge exchange.

Organizational knowledge is primarily embedded in the minds of the employees (called tacit knowledge) and in the activities, procedures, routines, processes and norms of the organization (known as explicit knowledge) [9]. The sharing of both tacit and explicit knowledge is very important and essential for the competitiveness of any business organization including healthcare institutions. However, there are factors that hinder the KS among employees of a given organization. These factors might be categorized into three: individual factors, organizational factors and technological factors [10].

The individual factors, which are influenced by willingness, awareness, past mistakes, trust, motivation, job satisfaction and fear of loss of personal competitiveness are the building blocks of the success of KS practices in organizations. The success of any KS practice depends largely on the communication among individuals, particularly sharing knowledge among the individuals. KS practice is among other reasons, related to the readiness of individuals to share their knowledge with others. However, effective KS among individuals depend on the individual KS behavior. Therefore, organizations may focus on the individual factors that influence KS behavior of individuals to have successful KS initiatives. Trust, awareness, willingness, job satisfaction, and intrinsic factor of motivation are categorized as individual factors [11].

In organizations, there are many ways of motivating and promoting KS practices. Knowledge exists in organizations and is influenced by organizational culture, management support, organizational structure, group interaction, reward, incentives, recognition and perceived openness [12]. However, its existence does not guarantee its utilization and dissemination among employees. Organizations' management of its knowledge resources can only be successful if it goes a long way to effectively facilitate knowledge sharing; to achieve maximum competitive advantage or successes within the organization. Therefore, organizations are required to build and maintain organizational factors that will support a KS environment [13].

Technology is said to be one of the knowledge management $(\mathrm{KM})$ infrastructures along with people and processes. [14] \& [15] believed that it is necessary to find technical ways in order to find, disseminate and utilize the knowledge. Information technology is usually said to be a good way for inter-organizational KS practice; especially for companies that are dispersed but want an environment which motivates people to share information, knowledge and best practices. It is also important to note that $\mathrm{KM}$ software needs to be integrated into the organizational culture, human resource as well as information technology (IT) infrastructure [11]. Also, companies on their part should consider technology which fits more with their employees and the organization [10]. However, technological factors are influenced by ICT infrastructure, usage, training and compatibility of ICT tools.

The concepts of knowledge and KS practices were described as a resource that employees should possess to effectively execute their tasks, while knowledge sharing practices/activities are sets of tasks that are used to share knowledge between knowledge owners and knowledge seekers [1]. The study revealed lack of teamwork, lack of communication channels, and lack of encouragement as hindering factors to KS practices. Besides, lack of skill and knowledge, lack of trust to peers was identified to be a major impediment for practicing the culture of KS. The lack of trust towards management was another hindrance. On the other hand, respondents' in the study did not perceive lack of policies and guidelines to hinder KS practices.

But [16] on barriers to KS and strategies to promote KS in an American based multinational company in Malaysia revealed that most of the respondents agreed that there was a KS strategy and a growing awareness of the benefit of KS in the organization. However, it was worrying to know that 22 percent of the study participants responded negatively to the statement that KS was important to the organization. Also, 27 percent of the respondents were not willing to share knowledge. The study pointed out that the most effective method to promote KS was to link it with rewards and performance appraisal. The top management support was considered vital to ensure the success of KS in the organization. Considering Cheng and Waiet.al studies it would be reasonable to note that individual and organizational factors can play a major role in knowledge sharing in organizations.

However, [17] on factors affecting employees' KS intention, KS behavior and innovation behavior in South Korea top ranked four university hospitals. The study used self-administered questionnaires to collect data. The researchers categorized factors influencing KS into individual factors (i.e. incentives, reciprocity, subjective norms and behavioral control) and organizational factors (i.e. organizational structure, administrative support, learning climate, IT systems, rewards systems and trust). The result generally revealed that behavioral control and trust were factors affecting hospital employees' KS intention, KS behavior and innovation behavior, which of course could be relative based on what contributions the IT 
systems could have made.

In Ethiopia, [18] study in FelegeHiwot Referral Hospital on KS among health professionals using a facility based cross-sectional study employing both quantitative and qualitative methods. The study included a total of 196 health professionals working in the Hospital. The study indicated that there was no frequent KS activity, due to lack of formal and informal KS opportunities. The hospital had no ICT infrastructures, which helped to facilitate KS. Due to lack of incentives and poor management support the respondents were not motivated to share knowledge. In the study, KS opportunity, communication channel, motivation, resource allocation and high education were found as an independent predictor of KS practices.

However, [29]; [20] \& [21] on assessment of KS practices of healthcare professionals showed that work experience, willingness, KS opportunity and intrinsic motivation were common independent predictors of KS practice in public and private hospitals; with association between KS practice and learning commitment in private hospitals. Also, motivation to transfer knowledge, salary increment, supportive leadership, KS opportunity were a significant predictor that affects healthcare professionals' KS practices, while job satisfaction, very high level of motivation, extrinsic motivation, use of communication channel and presence of KS opportunity were independent predictors of KS in hospitals.

But [22] on status of KS among health professionals indicated that the vast majority of the respondents (89\%) said that there was no KS strategy in Assosa Hospital. 73\% of the respondents disagreed on healthcare workers sharing their knowledge, work experience and ideas through group discussions, review meetings frequently and the participants (59\%) said there was no motivational scheme in hospital for KS practices.

In today's rapidly changing healthcare environment and health institutions (such as hospitals and clinics), optimization of chances and successes is not by telling healthcare professionals what to do, but by enabling them to make informed decisions. There is no health professional that knows everything he or she needs to know where his/her limitations are [23]. Health professionals need up-to-date health information from credible sources to improve their knowledge and provide evidence based healthcare services to their clients. In which case, having KS habits within the organizations will benefit health institutions and their customers by maximizing intellectual capital, minimizing costs, and making individuals and organizations stay competitive in their jobs and environments. Although, KS practices among different healthcare sectors are being acknowledged globally, it is also poorly practiced [7].

\section{Objective}

The objective of this study was to assess the current status and factors affecting knowledge sharing practices among health professionals in Hiwot Fana Specialize University Hospital (HFSUH) in Ethiopia.

\section{Methodology}

A Cross-sectional research method was employed for the study. The study was from the month of December 2018 to June 2019. Questionnaire instrument was used as a data collection tool to collect quantitative data from the participants. The participants were categories of health professionals in the Hiwot Fana Specialized University hospital (HFSUH) in Ethiopia that included: nurses, doctors, radiologists, laboratory technologists, health officers and pharmacists.

A sample size of 152 categories of health professionals comprising of 46 nurses, 18 doctors, 15 radiologists, 26 laboratory technologists, 22 health officers and 26 pharmacists were taken from a target population of 268 for the study. The sampling technique used for the selection of the categories of health professionals as respondents was stratified simple random sampling technique. This was because the population of heterogeneous and currently working in the HFSUH. The target population was first divided into uniform strata and then using a simple random sampling technique, the sample was selected [24].

The questionnaire items were prepared in English and used to collect relevant data from the 152 sample population of nurses, doctors, radiologists, laboratory technologists, health officers and pharmacists in HFSUH. It comprised only closed ended questions with five points Likert's scale intervals of 'strongly agreed/very high'; 'agreed/high'; 'undecided/medium'; 'disagreed/low' and 'strongly disagreed/very low'. It also covered the collection of data on the current status and the factors affecting KS practices in the HFSUH.

\section{Results}

\subsection{Response Rate}

Table 1. Response rate of participants

\begin{tabular}{|l|l|l|l|}
\hline S/N & Participants & Frequency & Percentages \\
\hline 1 & Pharmacists & 26 & $17.1 \%$ \\
\hline 2 & Nurses & 46 & $30.2 \%$ \\
\hline 3 & Health Officers & 22 & $14.4 \%$ \\
\hline 4 & Doctors & 18 & $11.8 \%$ \\
\hline 5 & Radiologists & 15 & $9.8 \%$ \\
\hline 6 & Laboratory technologists & 25 & $16.4 \%$ \\
\hline & Total & 152 & $99.7 \%$ \\
\hline
\end{tabular}

The response rate for the study was $152(100 \%)$ of the total sample population of $152(100 \%)$ of the study. The proportional distributions of the respondents were recorded 
as in Table 1 on the frequency and percentage response rate of participants in the study.

\subsection{Current Status of Knowledge Sharing Practices at HFSUH}

Knowledge sharing is about sharing relevant task (skills, experiences) among team members or with other people and making the shared knowledge reusable. Knowing the current status of KS practices of the categories of health professionals (i.e. Doctors, Nurses, Laboratory technologists, Radiologists, Health officers and Pharmacists) at the HFSUH becomes very necessary because it will help to determine the shortcomings of KS practices in the hospital and help in proposing a way to improve the practices. To analyze the data collected from the participants' questionnaire, the SPSS version 20, computer programme was used.

In Table 2 below, eight (8) items/KS variables on the current status of knowledge sharing practices among health professionals at HFSUH were measured on a five point scale, using an equal interval of 0.80 . The eight (8) items or KS variables were:

i) Staffs feeling motivated to share knowledge in the hospital.

ii) Availability of motivational scheme in the hospital to motivate knowledge sharing.

iii) There is periodic meetings in which people working in different departments participate in the hospital. iv) In the hospital there are formal opportunities like training programs and workshops that allow employees to share knowledge

v) It is individuals' pleasure to share their know-how, information, working experience and knowledge to their colleagues voluntarily.

vi) It is individuals' pleasure to share freely information and knowledge that improves the Hospital performance.

vii) Colleagues are willing to share information with other colleagues at all times in the hospital.

viii) Colleagues are aware of the importance of knowledge sharing on a daily basis in the hospital.

Thus the guideline below was used for interpreting the attitude mean scores of respondents in Table 2 on the current status of knowledge sharing practices among health professionals at HFSUH. The Table is divided into seven (7) columns as follows: serial numbering of the items/KS variables; the items/KS variables; categories of health professionals; responses; mean scores and decision column of the researchers, respectively.

A mean score was considered 'Very Low (VL)', if it falls within the range of 1.00 - 1.80; a mean score within the range 1.80 - 2.60 was taken as 'Low (L)'; a mean within the range 2.60 - 3.40 was considered 'Medium (M)', while a mean score within the range $3.40-4.20$ was taken as 'High $(\mathrm{H})$ '; and a mean score within the range 4.20 - 5.00 was considered 'Very High (VH)' for positive items [25].

Table 2. Current status of knowledge sharing of health professionals in the HFSUH

\begin{tabular}{|c|c|c|c|c|c|}
\hline $\mathbf{S} / \mathbf{N}$ & Knowledge sharing variables & Categories of Health professionals & Responses & $\mathbf{X}$ & Decision \\
\hline \multirow{7}{*}{1} & \multirow{7}{*}{$\begin{array}{l}\text { Staffs feeling motivated to } \\
\text { share knowledge in the hospital }\end{array}$} & Doctors & 15 & 2.27 & $\mathrm{~L}$ \\
\hline & & Nurses & 46 & 2.91 & M \\
\hline & & Laboratory technologists & 25 & 2.20 & $\mathrm{~L}$ \\
\hline & & Radiologists & 14 & 1.86 & $\mathrm{VL}$ \\
\hline & & Health officers & 21 & 2.10 & $\mathrm{~L}$ \\
\hline & & Pharmacists & 26 & 2.54 & $\mathrm{~L}$ \\
\hline & & Total & 147 & 2.44 & $\mathrm{~L}$ \\
\hline \multirow{7}{*}{2} & \multirow{7}{*}{$\begin{array}{l}\text { There were availability of } \\
\text { motivational scheme in the } \\
\text { hospital to motivate knowledge } \\
\text { sharing }\end{array}$} & Doctors & 15 & 1.87 & $\mathrm{~L}$ \\
\hline & & Nurses & 46 & 1.74 & $\mathrm{VL}$ \\
\hline & & Laboratory technologists & 25 & 1.84 & $\mathrm{~L}$ \\
\hline & & Radiologists & 14 & 1.79 & $\mathrm{VL}$ \\
\hline & & Health officers & 21 & 1.57 & $\mathrm{VL}$ \\
\hline & & Pharmacists & 26 & 1.69 & $\mathrm{VL}$ \\
\hline & & Total & 147 & 1.74 & $\mathrm{VL}$ \\
\hline \multirow{7}{*}{3} & \multirow{7}{*}{$\begin{array}{l}\text { In the hospital there were } \\
\text { periodic meetings in which } \\
\text { people working in different } \\
\text { departments participate }\end{array}$} & Doctors & 14 & 3.86 & $\mathrm{M}$ \\
\hline & & Nurses & 46 & 3.63 & $\mathrm{H}$ \\
\hline & & Laboratory technologists & 25 & 2.96 & M \\
\hline & & Radiologists & 14 & 3.21 & M \\
\hline & & Health officers & 21 & 3.10 & $\mathrm{M}$ \\
\hline & & Pharmacists & 26 & 3.08 & $\mathrm{M}$ \\
\hline & & Total & 146 & 3.32 & $\mathrm{M}$ \\
\hline
\end{tabular}


Table 2 Continued

\begin{tabular}{|c|c|c|c|c|c|}
\hline \multirow{7}{*}{4} & \multirow{7}{*}{$\begin{array}{l}\text { In the hospital there were } \\
\text { formal opportunities like } \\
\text { training programs and } \\
\text { workshops within the hospital } \\
\text { that allow employees to share } \\
\text { knowledge }\end{array}$} & Doctors & 15 & 4.07 & $\mathrm{H}$ \\
\hline & & Nurses & 46 & 3.20 & M \\
\hline & & Laboratory technologists & 25 & 3.36 & $\mathrm{H}$ \\
\hline & & Radiologists & 14 & 3.50 & $\mathrm{H}$ \\
\hline & & Health officers & 21 & 3.43 & $\mathrm{H}$ \\
\hline & & Pharmacists & 26 & 3.50 & $\mathrm{H}$ \\
\hline & & Total & 147 & 3.43 & $\mathrm{H}$ \\
\hline \multirow{7}{*}{5} & \multirow{7}{*}{$\begin{array}{l}\text { It was individuals' pleasure to } \\
\text { share their know-how, } \\
\text { information, working } \\
\text { experience and knowledge to } \\
\text { colleagues voluntarily }\end{array}$} & Doctors & 15 & 3.67 & $\mathrm{H}$ \\
\hline & & Nurses & 46 & 3.72 & $\mathrm{H}$ \\
\hline & & Laboratory technologists & 24 & 3.83 & $\mathrm{H}$ \\
\hline & & Radiologists & 14 & 4.14 & $\mathrm{H}$ \\
\hline & & Health officers & 20 & 4.15 & $\mathrm{H}$ \\
\hline & & Pharmacists & 26 & 3.58 & $\mathrm{H}$ \\
\hline & & Total & 145 & 3.81 & $\mathrm{H}$ \\
\hline \multirow{7}{*}{6} & \multirow{7}{*}{$\begin{array}{l}\text { It was individuals' pleasure to } \\
\text { share freely information and } \\
\text { knowledge that improves the } \\
\text { Hospital performance }\end{array}$} & Doctors & 15 & 3.73 & $\mathrm{H}$ \\
\hline & & Nurses & 45 & 3.84 & $\mathrm{H}$ \\
\hline & & Laboratory technologists & 25 & 3.96 & $\mathrm{H}$ \\
\hline & & Radiologists & 14 & 4.57 & $\mathrm{VH}$ \\
\hline & & Health officers & 21 & 3.95 & $\mathrm{H}$ \\
\hline & & Pharmacists & 26 & 4.19 & $\mathrm{H}$ \\
\hline & & Total & 146 & 4.00 & $\mathrm{H}$ \\
\hline \multirow{7}{*}{7} & \multirow{7}{*}{$\begin{array}{l}\text { Colleagues are willing to share } \\
\text { information with other } \\
\text { colleagues at all times in the } \\
\text { hospital. }\end{array}$} & Doctors & 15 & 4.07 & $\mathrm{H}$ \\
\hline & & Nurses & 46 & 3.43 & $\mathrm{H}$ \\
\hline & & Laboratory technologists & 24 & 3.50 & $\mathrm{H}$ \\
\hline & & Radiologists & 14 & 3.14 & M \\
\hline & & Health officers & 21 & 3.33 & $\mathrm{M}$ \\
\hline & & Pharmacists & 26 & 3.27 & M \\
\hline & & Total & 146 & 3.44 & $\mathrm{H}$ \\
\hline \multirow{7}{*}{8} & \multirow{7}{*}{$\begin{array}{l}\text { Colleagues are aware of the } \\
\text { importance of knowledge } \\
\text { sharing on daily basis in the } \\
\text { hospital }\end{array}$} & Doctors & 15 & 3.40 & $\mathrm{H}$ \\
\hline & & Nurses & 46 & 3.93 & $\mathrm{H}$ \\
\hline & & Laboratory technologists & 25 & 3.76 & $\mathrm{H}$ \\
\hline & & Radiologists & 13 & 4.00 & $\mathrm{H}$ \\
\hline & & Health officers & 21 & 4.19 & $\mathrm{H}$ \\
\hline & & Pharmacists & 26 & 4.00 & $\mathrm{H}$ \\
\hline & & Total & 146 & 3.90 & $\mathrm{H}$ \\
\hline
\end{tabular}

KEY

$\mathrm{X}=$ Mean

$\mathrm{VH}=$ Very High

$\mathrm{H}=$ High

$\mathrm{M}=$ Medium

$\mathrm{L}=\mathrm{Low}$

$\mathrm{VL}=$ Very Low 
Table 2 above was analyzed based on item analysis on the opinions of the categories of the health professionals that included: nurses, doctors, radiologists, laboratory technologists, health officers and pharmacists in the HFSUH. The items analysis showed that the current status of KS practices by all categories of health professionals was 'high' in items 4, 5, 6 and 8 (i.e. In the hospital there were formal opportunities like training programs and workshops within the hospital that allow employees to share knowledge (3.43); It was individuals' pleasure to share their know-how, information, working experience and knowledge to colleagues voluntarily (3.81); It is the individuals' pleasure to share freely information and knowledge that improves the Hospital performance (4.00) and Colleagues are aware of the importance of knowledge sharing on daily basis in the hospital (3.90), respectively).

But the availability of motivational scheme in the hospital to motivate knowledge sharing was 'very low' in item 2, i.e. There were availability of motivational scheme in the hospital to motivate knowledge sharing (1.74); they responded low in item 1, i.e. Staffs feeling motivated to share knowledge in the hospital (2.44) and finally the response was 'medium' in item 3 , i.e. In the hospital there were periodic meetings in which people working in different departments participate (3.32), respectively.

A cursory look at the individual categories on the items showed that Radiologists had a 'very high' KS practice in item 6 (i.e. It is individuals' pleasure to share freely information and knowledge that improves the Hospital performance), while they had 'very low' experiences in KS practices in items 1(i.e. Staffs feel motivated to share knowledge in the hospital) and 2 (i.e. There were availability of motivational scheme in the hospital to motivate knowledge sharing), although other categories like: nurses, health officers, and pharmacists had 'very low' in item 2.

\subsection{Factors Affecting Knowledge Sharing Practices in Hiwot Fana Specialized University Hospital}

Seventeen (17) variables were identified as factors affecting the six (6) categories of health professionals, who were: nurses, doctors, radiologists, laboratory technologists, health officers and pharmacists. The seventeen identified factors were addressed under three (3) categories of factors that included: individual factors, which had seven (7) components (i.e. willingness: awareness: past mistakes, trust, job satisfaction, intrinsic motivation and fear of loss personal competitiveness); organizational factors, which had six (6) components (i.e. organizational culture, management support, organizational structure, group interaction, reward and recognition, perceived openness) and technological factors that had four (4) components (i.e. ICT infrastructure, ICT Usage, ICT training and compatibility of ICT tools).

To analyze the data collected from the participants in questionnaire, the SPSS version 20, computer programme was used; as represented in Table 3 below on the factors affecting KS practices among health professionals in HFSUH. The factors were measured on a five point scale, using an equal interval of 0.80 . Thus the guideline used for interpreting the attitude mean scores of respondents in Table 3 shows that, a mean score was considered 'strongly disagreed (SD)', if it falls within the range of 1.00 - 1.80; a mean score within the range $1.80-2.60$ was taken as 'Disagreed (D)'; a mean within the range 2.60 - 3.40 was considered 'undecided (UD)', while a mean score within the range $3.40-4.20$ was taken as 'Agreed (A)'; and a mean score within the range 4.20 - 5.00 was considered 'strongly Agreed (SA)' for positive items [26]. 
Table 3. Factors affecting KS practices among health professionals in HFSUH

\begin{tabular}{|c|c|c|c|c|c|}
\hline $\mathrm{S} / \mathrm{N}$ & \multicolumn{2}{|c|}{ Factors affecting Knowledge Sharing Categories of health professionals } & $\mathbf{N}$ & Mean & Decision \\
\hline \multicolumn{6}{|c|}{ Individual factors } \\
\hline \multirow{7}{*}{1} & \multirow{7}{*}{$\begin{array}{l}\text { Lack of willingness by my colleagues to share their information with } \\
\text { other colleagues at all the time. }\end{array}$} & Doctor & 15 & 4.07 & A \\
\hline & & Nurse & 46 & 3.43 & A \\
\hline & & Laboratory technologist & 24 & 3.50 & A \\
\hline & & Radiologist & 14 & 3.14 & UD \\
\hline & & Health officers & 21 & 3.33 & UD \\
\hline & & Pharmacist & 26 & 3.27 & UD \\
\hline & & Total & 146 & 3.44 & A \\
\hline \multirow{7}{*}{2} & \multirow{7}{*}{$\begin{array}{l}\text { Lack of awareness on the importance of knowledge sharing in the day- } \\
\text { to- day work }\end{array}$} & Doctor & 15 & 3.40 & A \\
\hline & & Nurse & 46 & 3.93 & A \\
\hline & & Laboratory technologist & 25 & 3.76 & A \\
\hline & & Radiologist & 13 & 4.00 & A \\
\hline & & Health officers & 21 & 4.19 & A \\
\hline & & Pharmacist & 26 & 4.00 & A \\
\hline & & Total & 146 & 3.90 & A \\
\hline \multirow{7}{*}{3} & \multirow{7}{*}{$\begin{array}{l}\text { Lack of intrinsic motivation that staff would gain new ideas, technologies } \\
\text { skills or techniques by sharing knowledge }\end{array}$} & Doctor & 15 & 2.73 & UD \\
\hline & & Nurse & 46 & 3.52 & A \\
\hline & & Laboratory technologist & 25 & 3.92 & A \\
\hline & & Radiologist & 14 & 4.00 & $\mathrm{~A}$ \\
\hline & & Health officers & 21 & 3.52 & A \\
\hline & & Pharmacist & 25 & 3.60 & A \\
\hline & & Total & 146 & 3.57 & A \\
\hline \multirow{7}{*}{4} & \multirow{7}{*}{$\begin{array}{l}\text { In our organization past mistakes of employees are never solved by } \\
\text { giving training for those who made that mistake }\end{array}$} & Doctor & 15 & 2.07 & $\mathrm{D}$ \\
\hline & & Nurse & 46 & 3.22 & UD \\
\hline & & Laboratory technologist & 25 & 2.44 & $\mathrm{D}$ \\
\hline & & Radiologist & 14 & 2.50 & $\mathrm{D}$ \\
\hline & & Health officers & 21 & 2.81 & UD \\
\hline & & Pharmacist & 26 & 2.38 & $\mathrm{D}$ \\
\hline & & Total & 147 & 2.69 & UD \\
\hline \multirow{7}{*}{5} & \multirow{7}{*}{$\begin{array}{l}\text { Fearing the loss of personal competitiveness on sharing knowledge in my } \\
\text { organization }\end{array}$} & Doctor & 15 & 2.67 & UD \\
\hline & & Nurse & 46 & 2.09 & $\mathrm{D}$ \\
\hline & & Laboratory technologist & 25 & 2.24 & $\mathrm{D}$ \\
\hline & & Radiologist & 14 & 1.57 & $\mathrm{SD}$ \\
\hline & & Health officers & 21 & 2.57 & $\mathrm{D}$ \\
\hline & & Pharmacist & 26 & 2.27 & $\mathrm{D}$ \\
\hline & & Total & 147 & 2.22 & $\mathrm{D}$ \\
\hline \multirow{7}{*}{6} & \multirow{7}{*}{ Lack of trust of my co-workers hampers knowledge sharing } & Doctor & 15 & 3.00 & UD \\
\hline & & Nurse & 46 & 2.50 & $\mathrm{D}$ \\
\hline & & Laboratory technologist & 25 & 2.60 & UD \\
\hline & & Radiologist & 14 & 2.36 & $\mathrm{D}$ \\
\hline & & Health officers & 21 & 3.43 & A \\
\hline & & Pharmacist & 26 & 3.23 & UD \\
\hline & & Total & 147 & 2.82 & UD \\
\hline
\end{tabular}


Table 3 Continued

\begin{tabular}{|c|c|c|c|c|c|}
\hline \multirow{7}{*}{7} & \multirow{7}{*}{$\begin{array}{l}\text { Lack of job satisfaction in the organization reduce knowledge sharing } \\
\text { among colleagues }\end{array}$} & Doctor & 15 & 2.27 & $\mathrm{D}$ \\
\hline & & Nurse & 46 & 2.57 & $\mathrm{D}$ \\
\hline & & Laboratory technologist & 25 & 1.92 & $\mathrm{D}$ \\
\hline & & Radiologist & 14 & 2.07 & $\mathrm{D}$ \\
\hline & & Health officers & 21 & 2.76 & UD \\
\hline & & Pharmacist & 26 & 2.00 & $\mathrm{D}$ \\
\hline & & Total & 147 & 2.31 & $\mathrm{D}$ \\
\hline \multicolumn{6}{|c|}{ Organizational factors } \\
\hline \multirow{7}{*}{8} & \multirow{7}{*}{ Lack of organizational culture does not create knowledge sharing } & Doctor & 15 & 2.73 & UD \\
\hline & & Nurse & 46 & 2.85 & UD \\
\hline & & Laboratory technologist & 25 & 2.16 & $\mathrm{D}$ \\
\hline & & Radiologist & 14 & 1.71 & SD \\
\hline & & Health officers & 21 & 3.05 & UD \\
\hline & & Pharmacist & 26 & 2.08 & $\mathrm{D}$ \\
\hline & & Total & 147 & 2.50 & $\mathrm{D}$ \\
\hline \multirow{7}{*}{9} & \multirow{7}{*}{ Lack of management support knowledge sharing with colleagues } & Doctor & 15 & 2.40 & DUD \\
\hline & & Nurse & 46 & 2.65 & UD \\
\hline & & Laboratory technologist & 25 & 2.48 & $\mathrm{D}$ \\
\hline & & Radiologist & 14 & 2.14 & $\mathrm{D}$ \\
\hline & & Health officers & 21 & 2.71 & UD \\
\hline & & Pharmacist & 26 & 2.58 & $\mathrm{D}$ \\
\hline & & Total & 147 & 2.54 & $\mathrm{D}$ \\
\hline \multirow{7}{*}{10} & \multirow{7}{*}{ Lack of organizational structure in the hospital knowledge sharing } & Doctor & 15 & 2.60 & UD \\
\hline & & Nurse & 46 & 2.91 & UD \\
\hline & & Laboratory technologist & 25 & 2.56 & $\mathrm{D}$ \\
\hline & & Radiologist & 14 & 3.00 & UD \\
\hline & & Health officers & 21 & 2.71 & UD \\
\hline & & Pharmacist & 26 & 2.15 & $\mathrm{D}$ \\
\hline & & Total & 147 & 2.67 & UD \\
\hline \multirow{7}{*}{11} & \multirow{7}{*}{$\begin{array}{c}\text { Our organization does not encourage group interaction (team work) } \\
\text { regarding knowledge sharing }\end{array}$} & Doctor & 15 & 3.27 & UD \\
\hline & & Nurse & 46 & 3.35 & UD \\
\hline & & Laboratory technologist & 25 & 2.56 & $\mathrm{D}$ \\
\hline & & Radiologist & 14 & 2.64 & UD \\
\hline & & Health officers & 21 & 3.38 & UD \\
\hline & & Pharmacist & 26 & 2.54 & $\mathrm{D}$ \\
\hline & & Total & 147 & 3.00 & UD \\
\hline \multirow{7}{*}{12} & \multirow{7}{*}{$\begin{array}{l}\text { Most of the people I work with are not cooperative and open to share } \\
\text { knowledge }\end{array}$} & Doctor & 15 & 2.33 & $\mathrm{D}$ \\
\hline & & Nurse & 46 & 3.09 & UD \\
\hline & & Laboratory technologist & 25 & 2.32 & $\mathrm{D}$ \\
\hline & & Radiologist & 14 & 2.43 & $\mathrm{D}$ \\
\hline & & Health officers & 21 & 3.05 & UD \\
\hline & & Pharmacist & 26 & 2.46 & $\mathrm{D}$ \\
\hline & & Total & 147 & 2.70 & UD \\
\hline
\end{tabular}


Table 3 Continued

\begin{tabular}{|c|c|c|c|c|c|}
\hline \multirow{7}{*}{13} & \multirow{7}{*}{$\begin{array}{l}\text { In my organization individuals who share their knowledge are not } \\
\text { recognized and acknowledgement }\end{array}$} & Doctor & 15 & 2.47 & $\mathrm{D}$ \\
\hline & & Nurse & 46 & 3.09 & UD \\
\hline & & Laboratory technologist & 25 & 2.64 & UD \\
\hline & & Radiologist & 14 & 2.50 & $\mathrm{D}$ \\
\hline & & Health officers & 21 & 2.24 & $\mathrm{D}$ \\
\hline & & Pharmacist & 25 & 2.68 & UD \\
\hline & & Total & 146 & 2.70 & UD \\
\hline \multicolumn{6}{|c|}{ Technological factors } \\
\hline \multirow{7}{*}{14} & \multirow{7}{*}{ Lack of ICT infrastructure (internet, intranet) in the hospital } & Doctor & 15 & 3.13 & UD \\
\hline & & Nurse & 46 & 3.13 & UD \\
\hline & & Laboratory technologist & 25 & 2.88 & UD \\
\hline & & Radiologist & 14 & 2.07 & $\mathrm{D}$ \\
\hline & & Health officers & 20 & 3.50 & A \\
\hline & & Pharmacist & 26 & 3.08 & UD \\
\hline & & Total & 146 & 3.03 & UD \\
\hline \multirow{7}{*}{15} & \multirow{7}{*}{$\begin{array}{l}\text { There is lack of technical support and maintenance of integrated } \\
\text { Information Technology system }\end{array}$} & Doctor & 15 & 2.73 & UD \\
\hline & & Nurse & 45 & 3.58 & A \\
\hline & & Laboratory technologist & 25 & 2.84 & UD \\
\hline & & Radiologist & 14 & 2.07 & $\mathrm{D}$ \\
\hline & & Health officers & 21 & 2.90 & UD \\
\hline & & Pharmacist & 26 & 2.81 & UD \\
\hline & & Total & 146 & 2.99 & UD \\
\hline \multirow{7}{*}{16} & \multirow{7}{*}{$\begin{array}{l}\text { In the hospital, employees do not use knowledge networks such as } \\
\text { (email, intranet, internet) to communicate with colleagues }\end{array}$} & Doctor & 14 & 2.21 & $\mathrm{D}$ \\
\hline & & Nurse & 46 & 2.63 & UD \\
\hline & & Laboratory technologist & 25 & 2.04 & $\mathrm{D}$ \\
\hline & & Radiologist & 14 & 2.36 & $\mathrm{D}$ \\
\hline & & Health officers & 21 & 2.57 & $\mathrm{D}$ \\
\hline & & Pharmacist & 26 & 2.19 & $\mathrm{D}$ \\
\hline & & Total & 146 & 2.38 & $\mathrm{D}$ \\
\hline \multirow{7}{*}{17} & \multirow{7}{*}{$\begin{array}{c}\text { In our organization ICT tools are not easily used by employees of the } \\
\text { organization }\end{array}$} & Doctor & 15 & 2.60 & UD \\
\hline & & Nurse & 45 & 2.80 & UD \\
\hline & & Laboratory technologist & 25 & 2.00 & $\mathrm{D}$ \\
\hline & & Radiologist & 14 & 2.57 & $\mathrm{D}$ \\
\hline & & Health officers & 21 & 2.86 & UD \\
\hline & & Pharmacist & 26 & 2.58 & $\mathrm{D}$ \\
\hline & & Total & 146 & 2.59 & $\mathrm{D}$ \\
\hline
\end{tabular}

KEY

$\mathrm{SD}=$ Strongly Agreed

A $=$ Agreed

$\mathrm{UD}=$ Undecided

$\mathrm{D}=$ Disagreed

$\mathrm{SD}=$ Strongly Disagreed 
Table 3 above, shows that all categories of health professionals that include: nurses, doctors, radiologists, laboratory technologists, health officers and pharmacists in the HFSUH; 'agreed' that three (3) factors affect KS practices in the hospital. Such factors include items 1(i.e. Lack of willingness by my colleagues to share their information with other colleagues at all the time),2(i.e. Lack of awareness on the importance of knowledge sharing in the day- to- day work) and 3(i.e. Lack of intrinsic motivation that staff would gain new ideas, technologies skills or techniques by sharing knowledge). The items were categorized under individual factors, while the other two categories of organizational and technological factors did not have any item agreed upon.

However, the table also revealed that all categories of health professionals were 'undecided' on eight (8) of the factors. The factors were items 4(i.e. In our organization past mistakes of employees are never solved by giving training for those who made that), 6(i.e. Lack of trust of my co-workers hampers knowledge sharing),10(i.e. Lack of organizational structure in the hospital knowledge sharing),11(i.e. Our organization does not encourage group interaction (team work) regarding knowledge sharing),12(i.e. Most of the people I work with are not cooperative and open to share knowledge), 13(i.e. In my organization individuals who share their knowledge are not recognized and acknowledgement), 14(i.e. Lack of ICT infrastructure (internet, intranet) in the hospital) and 15(i.e. There is lack of technical support and maintenance of integrated Information Technology system).

From the KS factors that were 'undecided', items 4 \& 6 are categorized under individual factors. While four (4) items (i.e. items 10,11, 12 and 13) were categorized under organizational factors and two (2) others (i.e. 14 and 15) were from technological factors' category.

Although, the KS factors cut across the three (3) categories of KS factors affecting the categories of health professionals, the perception had a greater weighting coming from the organizational category; that had four (4) items (i.e. items 10, 11, 12 and 13), while individual and technological factors had two (2) items each (i.e. 4 and 6 as well as 14 and 15 respectively). On the perceived 'undecided factors' they could as well be considered problems that could affect KS practices in the hospital.

All categories of health professionals 'disagreed' on six (6) of the factors that fall in the three (3) categories of individual, organizational and technological factors as follows: two (2) items were in individual factors (i.e. items 5- 'Fearing the loss of personal competitiveness on sharing knowledge in my organization' and item 7- 'Lack of job satisfaction in the organization reduce knowledge sharing among colleagues', respectively); then two (2) items were from organizational factors (i.e. items 8 \& 9; being 'Lack of organizational culture does not create knowledge sharing' and 'Lack of management support knowledge sharing with colleagues', respectively) and two (2) other items were from technological factors (i.e. items 16 \& 17 that were: 'In the hospital, employees do not use knowledge networks such as (email, intranet, internet) to communicate with colleagues' and 'In our organization ICT tools are not easily used by employees of the organization', respectively).

It is safe to conclude therefore, that the identified factors affecting KS practices in HFSUH were: Lack of willingness by my colleagues to share their information with other colleagues all the time; Lack of awareness on the importance of knowledge sharing in the day- to- day work and Lack of intrinsic motivation that staff would gain new ideas, technologies skills or techniques by sharing knowledge. The items were categorized under individual factors without the inclusion of organizational and technological factors.

To identify the degree of statistical significance on the factors affecting KS practices in HFSUH, an inferential statistics was performed on the mean score of respondents in Table 4. A One-way analysis of variance (One-way ANOVA) statistic was used to test the significant differences that existed among the groups/categories of health professionals against the categories of factors that include individual factors, organizational factors and technological factors. 
Table 4. One-Way ANOVA test of significance on the categories of health professionals according to the factors

\begin{tabular}{|c|c|c|c|c|c|c|c|c|}
\hline $\mathrm{S} / \mathrm{N}$ & \multicolumn{2}{|l|}{ Item description CHP } & SS & Df & MS & $\mathrm{F}$ & Sig. & Remarks \\
\hline & \multicolumn{7}{|c|}{ Individual factors } & \\
\hline \multirow{3}{*}{1} & \multirow{3}{*}{$\begin{array}{l}\text { Lack of willingness by my colleagues to share their } \\
\text { information with other colleagues at all the time }\end{array}$} & Between Groups & 8.211 & 5 & 1.642 & 1.128 & .348 & NS \\
\hline & & Within Groups & 203.734 & 140 & 1.455 & & & \\
\hline & & Total & 211.945 & 145 & & & & \\
\hline \multirow{3}{*}{2} & \multirow{3}{*}{$\begin{array}{c}\text { Lack of awareness on the importance of knowledge } \\
\text { sharing in the day- to- day work }\end{array}$} & Between Groups & 6.455 & 5 & 1.291 & 1.479 & .200 & NS \\
\hline & & Within Groups & 122.202 & 140 & .873 & & & \\
\hline & & Total & 128.658 & 145 & & & & \\
\hline \multirow{3}{*}{3} & \multirow{3}{*}{$\begin{array}{c}\text { Lack of intrinsic motivation that staff would gain new } \\
\text { ideas, technologies skills or techniques by sharing } \\
\text { knowledge }\end{array}$} & Between Groups & 16.325 & 5 & 3.265 & 2.269 & .051 & NS \\
\hline & & Within Groups & 201.490 & 140 & 1.439 & & & \\
\hline & & Total & 217.815 & 145 & & & & \\
\hline \multirow{3}{*}{4} & \multirow{3}{*}{$\begin{array}{c}\text { In our organization past mistakes of employees are } \\
\text { never solved by giving training for those who made } \\
\text { that mistake }\end{array}$} & Between Groups & 23.413 & 5 & 4.683 & 2.343 & .044 & $\mathrm{~S}$ \\
\hline & & Within Groups & 281.811 & 141 & 1.999 & & & \\
\hline & & Total & 305.224 & 146 & & & & \\
\hline \multirow{3}{*}{5} & \multirow{3}{*}{$\begin{array}{l}\text { Lack of trust of my co-workers hampers knowledge } \\
\text { sharing }\end{array}$} & Between Groups & 21.568 & 5 & 4.314 & 2.759 & .021 & $\mathrm{~S}$ \\
\hline & & Within Groups & 220.473 & 141 & 1.564 & & & \\
\hline & & Total & 242.041 & 146 & & & & \\
\hline \multirow{3}{*}{6} & \multirow{3}{*}{$\begin{array}{l}\text { Fearing the loss of personal competitiveness on } \\
\text { sharing knowledge in my organization }\end{array}$} & Between Groups & 4.196 & 5 & .839 & .500 & .776 & NS \\
\hline & & Within Groups & 236.838 & 141 & 1.680 & & & \\
\hline & & Total & 241.034 & 146 & & & & \\
\hline \multirow{3}{*}{7} & \multirow{3}{*}{$\begin{array}{c}\text { Lack of job satisfaction in the organization reduce } \\
\text { knowledge sharing among colleagues }\end{array}$} & Between Groups & 32.059 & 5 & 6.412 & 3.624 & .004 & $\mathrm{~S}$ \\
\hline & & Within Groups & 249.451 & 141 & 1.769 & & & \\
\hline & & Total & 281.510 & 146 & & & & \\
\hline & \multicolumn{7}{|c|}{ Organizational factors } & \\
\hline \multirow{3}{*}{8} & \multirow{3}{*}{$\begin{array}{l}\text { Lack of organizational culture does not create } \\
\text { knowledge sharing }\end{array}$} & Between Groups & 8.916 & 5 & 1.783 & 1.010 & .414 & NS \\
\hline & & Within Groups & 247.146 & 140 & 1.765 & & & \\
\hline & & Total & 256.062 & 145 & & & & \\
\hline \multirow{3}{*}{9} & \multirow{3}{*}{$\begin{array}{l}\text { Lack of organizational structure in the hospital } \\
\text { knowledge sharing }\end{array}$} & Between Groups & 3.842 & 5 & .768 & .375 & .865 & NS \\
\hline & & Within Groups & 288.621 & 141 & 2.047 & & & \\
\hline & & Total & 292.463 & 146 & & & & \\
\hline \multirow{3}{*}{10} & \multirow{3}{*}{$\begin{array}{l}\text { I Lack of organizational structure in the hospital } \\
\text { knowledge sharing }\end{array}$} & Between Groups & 11.584 & 5 & 2.317 & 1.154 & .335 & NS \\
\hline & & Within Groups & 283.083 & 141 & 2.008 & & & \\
\hline & & Total & 294.667 & 146 & & & & \\
\hline
\end{tabular}


Table 4 Continued

\begin{tabular}{|c|c|c|c|c|c|c|c|c|}
\hline \multirow{3}{*}{11} & \multirow{3}{*}{$\begin{array}{c}\text { Our organization does not encourage group } \\
\text { interaction (team work) regarding knowledge sharing }\end{array}$} & Between Groups & 21.844 & 5 & 4.369 & 2.297 & .048 & $\mathrm{~S}$ \\
\hline & & Within Groups & 268.156 & 141 & 1.902 & & & \\
\hline & & Total & 290.000 & 146 & & & & \\
\hline \multirow{3}{*}{12} & \multirow{3}{*}{$\begin{array}{c}\text { Most of the people I work with are not cooperative } \\
\text { and open to share knowledge }\end{array}$} & Between Groups & 17.562 & 5 & 3.512 & 1.786 & .119 & NS \\
\hline & & Within Groups & 277.268 & 141 & 1.966 & & & \\
\hline & & Total & 294.830 & 146 & & & & \\
\hline \multirow{3}{*}{13} & \multirow{3}{*}{$\begin{array}{l}\text { In my organization individuals who share their } \\
\text { knowledge are not recognized and acknowledgement }\end{array}$} & Between Groups & 12.845 & 5 & 2.569 & 1.232 & .297 & NS \\
\hline & & Within Groups & 291.895 & 140 & 2.085 & & & \\
\hline & & Total & 304.740 & 145 & & & & \\
\hline & \multicolumn{7}{|c|}{ Technological factors } & \\
\hline \multirow{3}{*}{14} & \multirow{3}{*}{$\begin{array}{c}\text { Lack of ICT infrastructure (internet, intranet) in the } \\
\text { hospital }\end{array}$} & Between Groups & 18.525 & 5 & 3.705 & 2.302 & .048 & $\mathrm{~S}$ \\
\hline & & Within Groups & 225.365 & 140 & 1.610 & & & \\
\hline & & Total & 243.890 & 145 & & & & \\
\hline \multirow{3}{*}{15} & \multirow{3}{*}{$\begin{array}{c}\text { There is lack of technical support and maintenance of } \\
\text { integrated Information Technology system }\end{array}$} & Between Groups & 29.925 & 5 & 5.985 & 3.247 & .008 & $\mathrm{~S}$ \\
\hline & & Within Groups & 258.048 & 140 & 1.843 & & & \\
\hline & & Total & 287.973 & 145 & & & & \\
\hline \multirow{3}{*}{16} & \multirow{3}{*}{$\begin{array}{l}\text { In the hospital, employees do not use knowledge } \\
\text { networks such as ( email, intranet, internet) to } \\
\text { communicate with colleagues }\end{array}$} & Between Groups & 7.851 & 5 & 1.570 & .885 & .493 & NS \\
\hline & & Within Groups & 248.430 & 140 & 1.775 & & & \\
\hline & & Total & 256.281 & 145 & & & & \\
\hline \multirow{3}{*}{17} & \multirow{3}{*}{$\begin{array}{c}\text { In our organization ICT tools are not easily used by } \\
\text { employees of the organization }\end{array}$} & Between Groups & 12.196 & 5 & 2.439 & 1.617 & .159 & NS \\
\hline & & Within Groups & 211.146 & 140 & 1.508 & & & \\
\hline & & Total & 223.342 & 145 & & & & \\
\hline
\end{tabular}

*The mean difference is significant at the 0.05 level.*

Key

$\mathrm{CHP}=$ Categories of Health Professionals

$\mathrm{Df}=$ degree of freedom

SS $=$ Sum of squares

MS = Mean square

BG $=$ Between Groups

WG $=$ Within Groups

NS $=$ Not Significant

$\mathrm{S}=$ Significant 
Table 4 shows that the mean difference of the items of factors affecting KS practices of the categories of health professionals compared to 'between groups' and 'within groups' was significant on six (6) factors that included items $4,5,7,11,14 \& 15$ at the p-value $=<0.05$. The $\mathrm{p}$-values of the six (6) items were p-values $=<0.044 ; 0.021$; $0.002 ; 0.048 ; 0.048$ and 0.008 . The items were: on past mistakes of employees are never solved by giving training for those who made the mistakes in the organization; lack of trust of co-workers hampers knowledge sharing; lack of job satisfaction in the organization reduce knowledge sharing among colleagues; organization does not encourage group interaction (team work) regarding knowledge sharing; lack of ICT infrastructure (internet, intranet) in the hospital and lack of technical support and maintenance of integrated information technology system, respectively.

\section{Discussion}

The healthcare sector is a knowledge intensive organization, where sharing knowledge is important to achieve the intended goals and objective delivery of quality healthcare services. While the objective of this study was to assess the current status of knowledge sharing practices and identify the factors affecting knowledge sharing practices among health professionals in Hiwot Fana Specialized University Hospital. The study found that the current status of Knowledge Sharing practices by all categories of health professionals that include: nurses, doctors, radiologists, laboratory technologists, health officers and pharmacists vary according to their mean difference from 'high' to 'low' and to 'very low'. It is 'high' in areas such as: formal training programs and workshops within the hospital that allow employees to share knowledge (3.43); individuals' pleasure to share their know-how, information, working experience and knowledge to colleagues voluntarily (3.81); individuals' pleasure to share freely information and knowledge that improves the hospital performance (4.00) and colleagues awareness of the importance of knowledge sharing on daily basis in the hospital (3.90). These findings corroborate [29]; [19]; [27]; [28] \& [16] on knowledge sharing, which in today's rapidly changing healthcare environment health institutions (such as hospital and clinics) optimize their chance of success not by telling healthcare professionals what to do, but by enabling them to make informed decisions. There is no health professional that knows everything he or she needs to know through the context and content of knowledge possession, which are skills and resources found in employees and organizational processes that are embedded into different artifacts, procedures and stored into different media that are being shared. It is 'low' on staffs feeling of motivation to share knowledge in the hospital (2.44) and 'very low' in the area of availability of motivational scheme in the hospital to motivate knowledge sharing (1.74). These results also support or confirm the finding of [20] \& [22] that revealed health professionals need for up-to-date health information from credible sources to improve their knowledge and provide evidence based healthcare services to their clients. On having KS habits within the organizations, it will benefit health institutions and their customers by maximizing intellectual capital, minimizing costs, and making individuals and organizations to stay competitive in their environment. Also, participants' motivation to share their knowledge to colleagues will be enhanced; based on their engagement, the level of motivation and preferred motivational scheme in the organization.

Identifying factors affecting KS practices in organizations in general and the hospitals under study in particular; is important because it will increase the use of knowledge that already exists in the hospitals, which might be tacit or explicit. The factors affecting KS as categorized in this study were three factors: individual, organizational and technological factors [10]. From the One Way ANOVA tests of significant results, it was found that the factors affecting KS practices of the categories of health professionals at HFSUH were: past mistakes of employees are never solved by giving training for those who made the mistakes in the organization; lack of trust of co-workers hampers knowledge sharing; lack of job satisfaction in the organization reduce knowledge sharing among colleagues; organization does not encourage group interaction (team work) regarding knowledge sharing; lack of ICT infrastructure (internet, intranet) in the hospital and lack of technical support and maintenance of integrated information technology system. The results show an association with previous studies of [17] \& [18] that found hospital employees' knowledge sharing that were based on intention and behavior with innovational behavior.

\section{Conclusions}

Based on the objective and findings of this study that was on assess the current status of knowledge sharing practices and to identify the factors affecting knowledge sharing practices among health professionals in Hiwot Fana Specialized University Hospital, it is necessary to conclude that the current status and factors affecting knowledge sharing practices vary according to the categories of the health professionals feelings and opinions in the hospital. These categories of health professionals include: nurses, doctors, radiologists, laboratory technologists, health officers and pharmacists in the HFSUH. It is therefore the commitment of the hospital authority to consider addressing the factors that hinders the health professionals in the hospital to share their knowledge through developing an effective knowledge sharing framework and other knowledge sharing 
mechanisms.

\section{Acknowledgements}

We acknowledge with thanks to Haramaya University in Ethiopia for the financial support and facilitating the research work by providing the necessary facilities as well as providing support letter to the management of Hiwot Fana Specialized University Hospital to allow us conduct the study. Also, we would like to acknowledge Hiwot Fana Specialized University Hospital for her support during data collection for the study.

\section{REFERENCES}

[1] T. Assefa. Enabling Knowledge Sharing in the Workplace: The Case of Commercial Bank of Ethiopia (CBE). PhD dissertation, Addis Ababa University, Addis Ababa, Ethiopia, 2014.

[2] O. Y. Saatcioglu, O. N. Ozmen, E. D. Eris. A study on knowledge management and firm performance in Turkish IT sector. International Journal of Logistics Systems and Management, Vol. 11, No. 2, 213-231, 2012.

[3] S. S. Alam, Z. Abdullah, N. A. Ishak, Z. M. Zain. Assessing knowledge sharing behaviour among employees in SMEs: An empirical study. International Business Research, Vol. 2, No. 2, 115-122, 2009.

[4] S. S. Hosseini, T. Y. Nikkhah, A. Karami, Y. Jabarzadeh. The Impact of Knowledge Management Strategy on Service Innovation Performance in Private and Public Hospitals. Iranian Journal of Management Studies, Vol. 12, No. 1, 1-24, 2019.

[5] A. A. Alawneh, R. Aouf. A proposed knowledge management framework for boosting the success of information systems projects. In 2016 International Conference on Engineering \& MIS (ICEMIS), 1-5. IEEE, 2016

[6] A. Ghosh, A. Mahanti. Supporting Investment Advisors: A Knowledge Management Framework for Client and Prospect Intelligence. The IUP Journal ofKnowledge Management. Vol. 12, No. 3, 7-16, 2014.

[7] G. Dessie. Knowledge Sharing Practice and Associated Factors Among Health Care Workers at Public Hospitals in North Shoa, Amhara. American Journal of Health Research, Vol. 5, No. 5, 149-153, 2017.

[8] H. S. Lee. Knowledge management enablers and process in hospital organizations. Osong public health and research perspectives, Vol. 8, No. 1, 26-33, 2017.

[9] G. A. Guzman, J. Wilson, J. The "soft" dimension of organizational knowledge transfer. Journal of Knowledge Management, Vol. 9, No. 2, 59-74, 2005.

[10] A. Riege. Three-dozen knowledge-sharing barriers managers must consider. Journal of knowledge management, Vol. 9, No. 3, 18-35, 2005.

[11] N. M. Noor, J. Salim. Factors influencing employee knowledge sharing capabilities in electronic government agencies in Malaysia. International Journal of Computer Science Issues (IJCSI), Vol. 8, No. 4, 106-114, 2011.

[12] H. J. Hejase, Z. Haddad, B. A. Hamdar, H. Rola, A. Al, J. Ale, N. Beyrouti. Knowledge Sharing: Assessment of Factors Affecting Employee' Motivation and Behavior in the Lebanese Organizations. Journal of Scientific Research \& Reports (JSRR), Vol. 3, No. 12, 1549-1593, 2014.

[13] Z. T. Alhalhouli, Z. B. Hassan, A. M. Abualkishik. An updated model to enhance knowledge sharing among stakeholders in Jordanian hospitals using social networks. Middle-East Journal of Scientific Research, Vol. 18, No. 8, 1089-1098, 2013.

[14] G. Cepeda-Carrión. Competitive advantage of knowledge management. In Encyclopedia of Knowledge Management, Second Edition, 89-102. IGI Global, 2011.

[15] Y. Chun-zhou, L. Hua-yu, Z. Xi-chen, W. Hui-jin. Tacit knowledge management of scientific research work in universities. In 2011 International Conference on Computer Science and Service System (CSSS), 781-783. IEEE, 2011.

[16] C. Wai Ling, M.S. Sandhu, J.K. Kishore. Knowledge sharing in an American multinational company based in Malaysia. Journal of Workplace Learning, Vol. 21, No. 2, 125-142, 2009

[17] H.S. Lee, S.A. Hong. Factors affecting hospital employees' knowledge sharing intention and behavior, and innovation behavior. Osong public health and research perspectives, Vo.5, No. 3,148-155, 2014.

[18] A. Agmas. Knowledge sharing among health professionals: the case of Felegehiwot referral hospital. Msc thesis, Addis Ababa University, Addis Ababa, Ethiopia 2010.

[19] A. Ayele. Assessment of knowledge sharing practices and continuous learning commitment of health care professionals in hospitals in Hawassa, Ethiopia. Msc thesis, Addis Ababa University, Addis Ababa, Ethiopia, 2014.

[20] T. Gebretsadik, G. Mirutse, K. Tadesse, W. Terefe. Knowledge sharing practice and its associated factors of healthcare professionals of public hospitals, Mekelle, Northern Ethiopia. American Journal of Health Research, Vol. 2, No. 5, 241-246, 2014.

[21] T. Yalew. Assessment of Knowledge Sharing Practices of Healthcare Professionals in Hospitals under Addis Ababa Health Bureau. Msc thesis, Addis Ababa University, Addis Ababa, Ethiopia, 2011.

[22] C. Diriba, W. Jimma, D. Roba. Status of Knowledge Sharing Practices among Health Professionals the Mechanisms and Tools that Foster Knowledge Sharing: The Case of Assosa Hospital, Ethiopia, Journal of European Academic Research, Vol. 4, No. 8, 6628-6651, 2016.

[23] B.L. Motlanthe. Knowledge Sharing and Retention in South African Healthcare System: A Case of Chris Hani Baragwaneth Academic Hospital. Doctoral dissertation, Tshwane University of Technology, Tshwane, South Africa, 2017.

[24] U. Sekaran, R. Bougie. Research methods for business: A skill building approach, John Wiley and Sons, 2016.

[25] D. Roba, W. Jimma, C. Diriba. Individual, Organizational 
and Technological Factors Affect Knowledge Sharing Practices in Assosa Hospital, Ethiopia, European Academic Research, Vol. 4, No. 5, 2286-4822, 2016.

[26] L. A. Gojeh, L. I. Dutsc, H. Daudu. Human and Physical Environmental Factors affecting Student Utilization of Library and Information Services in Colleges of Educations Libraries in Nigeria, American International Journal of Research in Humanities, Vol. 3, No.1, 08-16, 2013.

[27] T. Assefa. Enabling Knowledge Sharing in the Workplace: The Case of Commercial Bank of Ethiopia (CBE). PhD dissertation, Addis Ababa University, Addis Ababa, Ethiopia, 2014

[28] O. Y. Saatcioglu, O. N. Ozmen, E. D. Eris. A study on knowledge management and firm performance in Turkish IT sector. International Journal of Logistics Systems and Management, Vol. 11, No. 2, 213-231, 2012.

[29] B. L. Motlanthe. Knowledge Sharing and Retention in South African Healthcare System: A Case of Chris Hani Baragwaneth Academic Hospital. Doctoral dissertation, Tshwane University of Technology, Tshwane, South Africa, 2017. 